\title{
OXYGEN REQUIREMENTS FOR THE MATURATION OF HAMSTER OOCYTES
}

\author{
R. B. L. GWATKIN AND A. A. HAIDRI \\ Merck Institute for Therapeutic Research, \\ Rahway, New Jersey 07065, U.S.A.
}

(Received 17th September 1973)

\begin{abstract}
Summary. Hamster oocytes exhibited a sharply defined optimum of $5 \% \mathrm{O}_{2}$ for maturation to metaphase II in vitro. Without the addition of $\mathrm{O}_{2}$, all of the oocytes were arrested during chromatin condensation. Under $10 \% \mathrm{O}_{2}$, most of the oocytes were arrested at several phases of meiosis up to and including telophase $I$.
\end{abstract}

Mammalian oocytes appear to require an oxygen concentration below $20 \%$ for optimal maturation in vitro. Thus, a greater proportion of mouse oocytes develop to metaphase II when the $\mathrm{O}_{2}$ concentration in the gas phase of the culture is reduced to 5 to $10 \%$ (Haidri, Miller \& Gwatkin, 1971). Recently, Gwatkin \& Haidri (1973) showed that hamster oocytes mature under 5\% $\mathrm{O}_{2}$ but rapidly become necrotic under $20 \% \mathrm{O}_{2}$. This prompted us to determine the effect of varying the $\mathrm{O}_{2}$ concentration on the proportion of hamster oocytes undergoing maturation to metaphase II. The results of these studies are reported in this communication.

Employing methods already described (Gwatkin \& Haidri, 1973), oocytes, free of cumulus cells, were collected under an air atmosphere from the enlarged follicles present in the ovaries of 9- to 10-week-old golden hamsters (Mesocricetus auratus) which had been injected intraperitoneally 3 days previously with 25 i.u. PMSG (Organon). These oocytes were cultured in medium GH-2 (Haidri \& Gwatkin, 1973) in Microtest Plates (Cat. No. 3034, Falcon Plastics) without an oil cover.

Medium GH-2 consists of a balanced salt solution, energy sources (pyruvate, lactate and glucose), twelve amino acids and crystalline bovine serum albumin. The amino acids and albumin were shown to be essential for maximum polar body formation by preovulatory oocytes (Haidri \& Gwatkin, 1973). The three energy sources can be omitted without reducing the proportion of oocytes maturing (R. B. L. Gwatkin and A. A. Haidri, unpublished data). These needs are presumably met by gluconeogenesis from one or more of the amino acids.

The cultures were placed in small desiccators, which were evacuated to $60 \mathrm{~mm}$ $\mathrm{Hg}$ and refilled three times with atmospheres containing various partial pressures of $\mathrm{O}_{2}$. The balance of each atmosphere was nitrogen, except for $\mathrm{CO}_{2}$ which was kept constant at $5 \%$. After $16 \mathrm{hr}$, the proportion of oocytes which had formed polar bodies was recorded. Text-figure 1 shows that under $5 \%$ $\mathrm{O}_{2}$, the optimum concentration, approximately $90 \%$ of the oocytes formed 


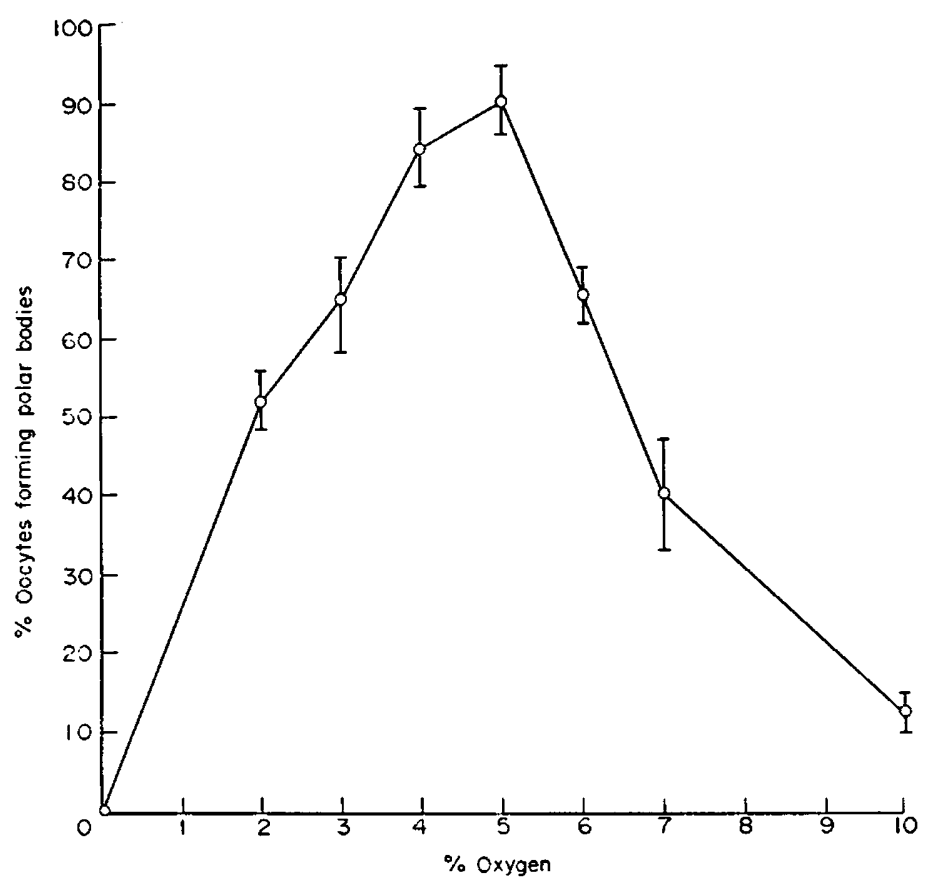

TexT-FIG. 1. Effect of $\mathrm{O}_{2}$ concentration on the percentage of hamster oocytes which formed polar bodies. Gircles represent means of four experiments, each employing groups of ten oocytes. Vertical bars represent standard deviations.

a polar body. Both at lower and at higher $\mathrm{O}_{2}$ concentrations, there was a sharp decline in polar body formation. At $10 \% \mathrm{O}_{2}$, less than $15 \%$ of oocytes formed polar bodies, although they remained otherwise normal in appearance. Increasing the $\mathrm{O}_{2}$ concentration to $20 \%$ produced necrosis within $5 \mathrm{hr}$.

In order to determine the stage of meiotic arrest produced by a lack or an excess of $\mathrm{O}_{2}$, oocytes were incubated for $16 \mathrm{hr}$ without the addition of $\mathrm{O}_{2}$ to the gas phase and in the presence of $10 \% \mathrm{O}_{2}$. The cultured oocytes were then stained with aceto-orcein (Donahue, 1968). Table 1 shows that all of the control oocytes incubated in $5 \% \mathrm{O}_{2}$ progressed to metaphase II. Without this addition, however, there was hardly any nuclear progression. The only change apparent was a condensation of the chromatin which resembled the stage designated by Donahue (1968) in the mouse as 'chromatin II'. Under $10 \%$

Table 1. The effect of $\mathrm{O}_{2}$ concentration on the nuclear progression of hamster oocytes

\begin{tabular}{c|c|c|c|c|c|c}
\hline \multirow{3}{*}{$\% \mathrm{O}_{2}$} & \multirow{2}{*}{$\begin{array}{c}\text { No. } \\
\text { of } \\
\text { oocytes }\end{array}$} & \multicolumn{5}{|c}{ No. of oocytes reaching: } \\
\cline { 3 - 7 } & $\begin{array}{c}\text { Chamined } \\
\text { examatin }\end{array}$ & Metaphase & Anaphase & Telophase & Metaphase \\
& & $I$ & $I$ & $I$ & $I I$ \\
\hline 0 & 22 & 22 & 0 & 0 & 0 & 0 \\
5 & 17 & 0 & 0 & 0 & 0 & 17 \\
10 & 17 & 0 & 9 & 2 & 3 & 3 \\
\hline
\end{tabular}


$\mathrm{O}_{2}$, most of the oocytes were arrested in metaphase I while the remainder progressed to anaphase, telophase or metaphase II.

These studies demonstrate that there is a sharply defined optimum of $5 \%$ $\mathrm{O}_{2}$ for the maturation of hamster oocytes. This is in agreement with the limited information which is available concerning the $\mathrm{O}_{2}$ environment within the mammalian follicle. Thus, Birnberg \& Gross (1958) showed that there is an active reductase system operating in human follicular fluid. Fraser, Baird \& Cockburn (1973) reported that the 'oxygen tension of human follicular fluid may be substantially lower than that of peripheral or ovarian venous blood'.

This apparent requirement of the mammalian oocyte for a relatively anaerobic environment appears to continue after ovulation, since Whitten (1970) showed that mouse zygotes require a reduced $\mathrm{O}_{2}$ concentration for cleavage. The oil cover used by most investigators to culture mammalian oocytes and cleavage stages probably masks this requirement by restricting $\mathrm{O}_{2}$ exchange (Gwatkin, 1972).

The mechanism by which $\mathrm{O}_{2}$ concentrations in excess of $5 \%$ block the maturation of hamster oocytes is not known. It could be that excess $\mathrm{O}_{2}$ acts by a Pasteur effect, i.e. it inhibits anaerobic glycolysis, which is active in early embryonic development (Fridhandler, 1961). If so, this would suggest that anaerobic as well as aerobic glycolysis is involved in supplying the energy required for these steps in meiosis.

\section{REFERENGES}

Birnberg, C. H. \& Gross, M. (1958) Enzymatic activities of follicular fluid. Int. F. Fert. 3, 374.

Donahue, R. P. (1968) Maturation of the mouse oocyte in vitro. I. Sequence and timing of nuclear progression. F. exp. Zool. 169, 237.

Fraser, I. S., Baird, D. T. \& Cockburn, F. (1973) Ovarian venous blood $\mathrm{PO}_{2}, \mathrm{PCO}_{2}$ and $\mathrm{pH}$ in women. F. Reprod. Fert. 33, 11.

Fridhandler, L. (1961) Pathways of glucose metabolism in fertilized rabbit ova at various pre-implantation stages. Expl Cell Res. 22, 303.

Gwatkin, R. B. L. (1972) Chemically defined media for mammalian eggs and early embryos. In Vitro, 8, 59.

Gwatkin, R. B. L. \& Haidri, A. A. (1973) Requirements for the maturation of hamster oocytes in vitro. Expl Cell Res. 76, 1.

HAIDRI, A. A. \& GWATKIN, R. B. L. (1973) Requirements for the maturation of hamster oocytes from preovulatory follicles. 7. Reprod. Fert. 35, 173.

Haidri, A. A., Miller, J. M. \& GWatkin, R. B. L. (1971) Culture of mouse oocytes in vitro, using a system without oil or protein. J. Reprod. Fert. 26, 409.

Whitten, W. K. (1970) Nutrient requirements for the culture of preimplantation embryos. Adv. Biosci. 6, 129. 